Estudios Románicos, Volumen 29, 2020, pp. 29-42

ISSN: 0210-4911

eISSN: $1989-614 \mathrm{X}$

DOI: https://doi.org/10.6018/ER.425711

\title{
UN PASEO POR LOS PAISAJES POÉTICOS \\ DE ANTONIO GALA: EL POEMA DE TOBÍAS \\ DESANGELADO EN CLAVE DE LÍRICA DE VIAJES
}

(A Walk Through Antonio Gala's Poetic Landscapes:

El poema de Tobías desangelado in Travel Lyric Poetry Key)

\section{Pedro J. Plaza González* \\ Universidad de Málaga}

\begin{abstract}
Compared to his theatrical production or his novels, Antonio Gala's poetry has been much less studied by the academy. In this article, an approach to Gala's poetry is made, specifically to his book El poema de Tobías desangelado (2005), proposing a reading, among other possible ones, of the book of poems, which is a peregrinatio vitae and a peregrinatio amoris too, in terms of travel lyric poetry in particular and in terms of travel literature in general. To do this, taking the work of Idoia Arbillaga as the main reference, the specific rhetorical issues of the genre present in the text are analyzed and exemplified - inventio, dispositio, elocutio - and all the elements related to the trip, also to the path and to the landscape, that Gala gathers in his poems, are collected and organized - the vehicles used, the contact with other cultures, their religions, their monuments, the companion, and so on-.
\end{abstract}

Keywords: Antonio Gala; El poema de Tobías desangelado; Travels' lyric poetry; Peregrinatio; Homo viator; Landcapes.

Resumen: Frente a su producción teatral o a sus novelas, la poesía de Antonio Gala ha sido mucho menos estudiada por la academia. En este artículo se realiza un acercamiento a la poesía de Gala, en concreto a su libro El poema de Tobías desangelado (2005). Se propone una lectura, entre otras posibles, del poemario, que es una peregrinatio vitae y una peregrinatio amoris, en clave de lírica de viajes en particular y en clave de literatura de viajes en general. Para ello, tomando como referencia principal el tra-

* Dirección para correspondencia: Pedro J. Plaza González. Departamento de Filología Española, Italiana, Románica, Teoría de la Literatura y Literatura Comparada. Facultad de Filosofía y Letras. Universidad de Málaga. Campus de Teatinos.29071 Málaga (pjplazagonza@uma.es). 
bajo de Idoia Arbillaga, se analiza y ejemplifica la concreción de las cuestiones retóricas propias del género presentes en el texto -inventio, dispositio, elocutio - y se recopilan, organizan y analizan todos los elementos relativos al viaje, al paseo y al paisaje que Gala reúne en sus poemas - los vehículos utilizados, el contacto con otras culturas, sus religiones, sus monumentos, el compañero de peripecias, etcétera-.

Palabras clave: Antonio Gala; El poema de Tobías desangelado; Lírica de viajes; Peregrinatio; Homo viator; Paisajes.

Viajar a Marte o al cuarto de la plancha. Pero contigo. Luis Alberto de Cuenca

\section{Una cuestión genérica. La lírica de viajes: una singularidad literaria}

Como bien han puesto de relieve Clara Cobo Guijarro y Ana Padilla Mangas en su más reciente revisión bibliográfica relativa a la crítica sobre su obra, "[...] la poesía de Antonio Gala es el género más descuidado en el conjunto de los estudios académicos, a pesar de que fue su ejercicio literario más temprano" (Cobo Guijarro y Padilla Mangas 2019: 393). No obstante, el presente artículo no aborda sus inicios, sino, por el contrario, sus últimos ejercicios poéticos, pues, según las palabras del propio Gala, El poema de Tobías desangelado resulta ser su mayor legado para la posteridad, ya que "[...] plasma su vida en forma de «testamento literario»" (EFE 2005).

El poemario que nos ocupa fue publicado por la Editorial Planeta en el año 2005 y se erige, a la sazón, como una especie de diario personal de viajes, al estilo del que compuso el nobel Juan Ramón Jiménez en su Diario de un poeta reciencasado (Jiménez 2011: 95-300). Sucede que, verdaderamente, Gala portó siempre consigo un cuaderno blanco, el cual se conserva hoy por hoy en el seno de la Fundación Antonio Gala para Jóvenes Creadores de Córdoba, dentro de una vitrina de la exposición permanente llamada "Recuerdos de Antonio Gala". Este cuaderno fue comprado, precisamente, en Jerusalén durante uno de sus cuantiosos viajes y en él sentía, de tanto en tanto, la necesidad imperiosa de escribir mientras paseaba por la ciudad visitada, a la luz de su fisionomía urbana, y, en consecuencia, se paraba en el sitio más oportuno para poder garabatear algunos versos. Hay, incluso, alguna que otra prueba fotográfica de este hecho (Rubio 2016: 157). Con el paso de los años, otros cuadernos, libretas y hojas sueltas sustituirían al susodicho y cobijarían los manuscritos del futuro poemario.

De esta guisa, paralelamente a su naturaleza, indiscutible, de cancionero, la cual no es momento ahora de desarrollar en este artículo — otra será, en efecto, la ocasión-, el texto que tenemos entre manos puede ser, de igual modo, un cuaderno de bitácora y, por ende, habría de inserirse dentro del rico y amplio género de la literatura de viajes, tan en boga, consintiendo siempre un diálogo entre el ser humano y la urbe que posee las siguientes características: 
El hombre aprehende su entorno a través del lenguaje, y la ciudad, a su vez, genera un lenguaje propio y obliga al hombre a hablar con las palabras del café, del bulevar, del mercado, etc. En este sentido, los escritores serían los lectores privilegiados de la ciudad; pues si la ciudad se expresa y habla a todos sus habitantes, a todos los individuos que la observan y la recorren, no todos son capaces de comprenderla, de interpretar su lenguaje [...] (Peñalta Catalán 2014: 19).

Por esta razón, me dispongo a rastrear a través de sus más de trescientas páginas las características definitorias de tal género, siguiendo, esencialmente, la teoría expuesta por Idoia Arbillaga (2005) en su celebrado volumen y procediendo con una metodología de carácter deductivo, en tanto en cuanto la aproximación se mueve desde los rasgos generales de la literatura de viajes hasta el caso particular de El poema de Tobías desangelado. La hipótesis, en fin, parte de las pretensiones del propio Gala (Infante 1994: 157) y de los atisbos, reformulados, de José Manuel Caballero Bonald:

[...] emulando el peregrinaje de Tobías traza un cuaderno de ruta, glosando en clave lírica sus experiencias de viajero por medio mundo. La geografía física y humana equivale al argumento de su historia personal. Dice Gala que Tobías desangelado viene a ser como una crónica de los viajes del protagonista desprovisto ya de la presencia humana tangible, protectora y deseada del ángel, son sus palabras (Caballero Bonald 2011: 31).

Cabe realizar, en este punto, una mínima reflexión. Si, finalmente, con el análisis de este aspecto nos convencemos de dicha asunción, nos hallaremos ante algo casi inaudito en el horizonte literario; ¿y por qué? Porque la poesía no ha sido estudiada ni debida ni suficientemente como posible receptáculo de la llamada literatura de viajes, aunque hemos de recordar la existencia de diferentes descripciones de diferentes ciudades en el Siglo de Oro, por ejemplo, dentro del género de la épica culta (Lara Garrido 1999: 209 y ss.). Esta pudiera servir de antecedente lejano de lo que en adelante llamaré lírica de viajes, y fue perdiendo fuerza y protagonismo progresivamente hasta principios del siglo XIX. Asimismo, hemos de recordar que "Bailly va más allá e identifica unas ciudades con textos en prosa y otras con poemas [...]" (Peñalta Catalán 2014: 19). José María Santos Rovira y Pablo Encinas Arquero, sin embargo, sostienen una opinión bastante más extrema que no ha llegado a calar, puesto que esgrimen que "[...] la literatura de viajes no debe quedar reducida a ser un subgénero o grupo temático, ya sea de la narrativa o de cualquier otro, sino que debe gozar del estatus de ser un género literario propio [...]" (Santos Rovira y Encinas Arquero 2009). A mi parecer, esta postura resulta confusa y poco operativa en la labor filológica, dado que la evolución de la división aristotélica desde la Antigüedad hasta nuestros días ha desembocado en una diferenciación entre narrativa, poesía y teatro de carácter formal - aunque sus límites sean en ocasiones borrosos- (Garrido Gallardo 1994: 165) y, por ende, podemos entender muchos de los subgéneros literarios de forma transversal a causa de su temática. Tal es el caso de la literatura de viajes, pese al descuido de la poesía en su recepción y la 
consecuente problemática. Con todo, sí parece antojarse oportuna una nueva etiqueta en el marco de la literatura de viajes: la lírica de viajes, esto es, la poesía que recoge los acontecimientos, los sentimientos y las impresiones de un viajero, pudiendo tratarse tanto de viajes reales como de viajes fantásticos. Esta posible etiqueta no fue contemplada ni siquiera por Arbillaga. La autora, por un lado, consideraba que el conflicto existía con los géneros ensayísticos y con los géneros narrativos (Arbillaga 2005: 95); por otro lado, señalaba que la subdivisión se concretaba, fundamentalmente, en tres modelos: el diario, la memoria y la carta (Arbillaga 2005: 101).

En El poema de Tobías desangelado las facetas del poeta de cancionero, de homo viator y de viajante en dos puntos gemelos se unen, convergen: la peregrinatio vitae física y la peregrinatio amoris espiritual que descubriremos en este paseo por la poesía de Antonio Gala con objeto de dilucidar sus paisajes exteriores e interiores. Tras haberse publicado bajo el nombre de Tobías desangelado por primera vez en la antología Poemas de amor, es decir, en 1997, la disolución de ambos modos de peregrinatio cobra un sentido completo o, según Francisco Díaz de Castro, quien reseñara prontamente el libro de forma impresionista, posibilita un viaje no solo exterior, sino también interior:

Ahora, con numerosas variantes y, sobre todo, con una estructura orgánica nueva que aporta mayor profundidad al argumento de este poema de poemas, el autor nos invita a un viaje al interior de nuestra conciencia sentimental a partir de lo que es también un homenaje personal a la realidad vivida del mundo [...] (Díaz de Castro 2005).

\section{Tras los pasos de los rasgos discursivos: inventio, dispositio, elocutio. Retórica de la literatura de viajes en El poema de Tobías desangelado}

"He viajado mucho. A veces pienso que más de lo que habría querido; a veces pienso que casi todo lo aprendí viajando. No al llegar al punto de destino: al ir hacia él. Creo que el camino significa y enseña más que la posada" (Gala 2000: 276), declaraba Gala en su peculiar autobiografía, Ahora hablaré de mí, y luego en la página guía del primer volumen de los Quaderni Mediterranei (Gala 2018: 15), editado por los italianos Silvestro Neri y Lorenzo Cittadini. Para ubicarnos en la lectura de El poema de Tobías desangelado como libro de viajes, la cual se extrapola en clave de lírica de viajes, las coordenadas tangenciales que delineó Arbillaga (2005: 69-94) serán, como ya he dicho $a$ priori, el mapa en el presente asedio, tomando de su trabajo los elementos aquí tasados.

Ocurre que, en la actualidad, el suculento género temático de la literatura de viajes goza de gran popularidad entre los estudiosos hispánicos ${ }^{1}$, auspiciando, por error, que no hay mucho más que prosa en la fértil tierra donde germina. Y - lo adelantaba en la introducción-, si bien es cierto que al pasear hechizados por las hojas del Diario de un poeta reciencasado nos llevaremos la probable idea de haber buceado en las profundidades de la literatura de viajes, no es menos cierto que la mayor parte del Diario está conce-

1 Otras referencias de interés en la materia de la literatura de viajes que aquí han sido objeto de consulta son Urbain (1993), Salcines de Delás (1995) o Alburquerque García (2011). 
bida en prosa. "Prosa poética, o poemas en prosa", argumentarán algunos —y quizás el componente maravilloso del transitar por el mundo es, motu proprio, ya irrevocablemente lírico-, mas prosa, al fin y al cabo; por ello, se asemeja tan original la obra que nos concierne, inminentemente escrita, en su totalidad — hasta en sus agradecimientos-, en verso peregrino. Pese a todo, he de conceder que el Diario juanramoniano se posiciona por méritos sobrados como precedente, y hay, aun, un posible descendiente intitulado con un agudo juego de palabras: Polisgamia, de Miguel Ángel Arenas Haro. En ese proyecto - todavía inacabado, puesto que ha viajado a más de sesenta países - literaturizaba el autor sus paseos y sus aventuras por Nueva York, Atenas, Venecia, Moscú, Buenos Aires y París (Arenas Haro 2005), ciertamente con impulsos comunes a los de Kavafis (1997: 47) o a los de Gala (2005: 97-98): "Atenas, madre de las ítacas de cada uno, / prometo que no le contaré a nadie lo de nuestro incesto" (Arenas Haro 2005: 30). Otro descendiente plausible es Cortes de luz, de Victoria Aranda, quien fuera becaria de la Fundación Antonio Gala durante el curso 2005/2006, perteneciendo, pues, a la cuarta promoción. En este poemario, accésit del Premio Adonáis en 2009, la escritora daba cuenta de su estancia en India y bautizaba buena parte de los poemas con los nombres de sus ciudades, por ejemplo: «Bombay», «Madrás», «Calcuta», «Plaza de los alfareros (Bhaktapur)» (Aranda 2010: 21, 26, 28 y 64). Tal y como subraya Julio Neira, es interesante rescatar la figura de Guillermo Díaz-Plaja — quien, por cierto, ha estudiado el teatro de Gala-, dado que "[...] los libros de viajes son una parte notable de [su obra]" (Neira 2012: 132). Mientras Gala reúne en un solo volumen todos sus viajes, Díaz-Plaja, exponente, sin duda, de la lírica de viajes, los produjo y publicó, por el contrario, en compartimentos estancos: $L a$ soledad caminante. Poemas del Norte de América (1966), África por la cintura: notas a un safari fotográfico (1967), América vibra en mí (1969), Poemas de Oceanía (1972), Poemas en el mar de Grecia (1973), Poemas y canciones del Brasil (1974).

En otro derrotero, el Testamento andaluz de Antonio Gala, con su tour por Andalucía, le sirve a sí mismo de íntimo antecedente para lo disolución de lo exterior en lo interior, dialogando, por ejemplo, con nuestra tradición mística: "Fue a la vera del mar, a medianoche. / Supe que estaba Dios, / y que la arena y tú / y el mar y yo y la luna / éramos Dios. Y lo adoré" (Gala 1998: 16); o dialogando, al revisitar Ronda, con Rilke: "Nada está fuera de su sitio aquí. / Luminosa y en alto, / la ciudad nos sosiega" (Gala 1998: 17).

De este modo, es hora de definir ya el quid de la cuestión para comprobar, mediante un razonamiento deductivo, si el producto se adapta al molde encomendado para la ocasión y es, en efecto, El poema de Tobías desangelado parte de la literatura de viajes en general y paradigma de la lírica de viajes en particular. Según Arbillaga, podemos, en síntesis, delimitar el género así - la primera cursiva es mía para señalar el cuestionamiento expuesto anteriormente- :

[...] es un género ensayístico que presenta una predeterminación temática, la cual requiere eminentemente la descripción de un viaje real que es representado mediante el desarrollo de un itinerario topográfico pleno, parcial o implícito. Su dispositio se constituye cardinalmente por razón del discurso descriptivo, seguido del narrativo, y 
su elocutio se manifiesta mediante la preferencia por la primera persona, por la virtud de la perspicuitas, por el estilo medio o bien epistolar, y por el uso característico, si no privativo, de ciertas figuras retóricas como el recurso a otras obras y otros procedimientos formales (Arbillaga 2005: 94).

Partiendo desde este punto cardinal, recojo el guante entretejido de pilares retóricos que Arbillaga tiende. Si vamos al comienzo, es claro, sin atisbo de duda, que la inventio concuerda desde los albores del texto galiano - se trata de una peregrinatio vitae por cuatro continentes, a falta de Oceanía - y, de esa suerte, se anuncia al intrépido lector, quien lee en la contracubierta azulada del libro: "Esta es la historia / de un viaje enamorado" (Gala 2005). ¿Y qué descubre al hurgar, intrigado, en sus entrañas? Dos cosas: la primera, que se trata de un poema de poemas; la segunda, que se nos invita a un viaje sembrado, en realidad, de muchísimos viajes, y es fácil deducirlo solo ojeando los títulos en cursiva, ya que cada poema lleva por título el nombre de una ciudad o similar.

Por otro lado, encontramos en gran medida la misma dicotomía que señalaba Arbillaga (2005: 74-86) en la dispositio que vertebra el Tobías. A mi juicio, el discurso narrativo se ha reservado especialmente para guiar el hilo argumental del cancionero - otras de las lecturas del libro- que subyace en sus distintas y encandiladoras secuencias. Entretanto, el discurso descriptivo se ha utilizado preeminentemente a la hora de describir el maremágnum de lugares que fueron visitados — con ánimo denotativo y connotativo-. Daré velozmente solo un par de muestras del corpus. En un museo de México, por ejemplo, escribía, combinando lo botánico y lo zoológico:

\author{
Sobre el nopal y el agua \\ volaba el águila devorando al reptil. \\ Hay en su nido plumas \\ de pájaros azules y rojos. \\ Y el águila, ante los hijos del Sol, \\ inclinó su cabeza. \\ La cabeza del rey será la decorada con penachos \\ de plumas de Quetzal, \\ donde la luz se instala y se complace, \\ y los de otros pájaros desaparecidos (Gala 2005: 75).
}

Y en Umeä figuraba, pictóricamente, los detalles del arte contemplado: "Recuerdo aquel cuadro / del invierno. Brüghel el Viejo / pintó la soledad muy blanca / en la plaza del pueblo. El cielo / casi al alcance de la mano, / el silencio en los gestos, la luz tan yerta y muda, / la tenue serenidad de los objetos..." (Gala 2005: 239).

En cuanto a la elocutio, ha de ser, estrofa a estrofa, la primera persona la empleada para la escritura del cancionero, y es, coincidente, esa primera persona la que enfoca la lente del libro de viajes, pues es el viajero el que se alegra o se duele de lo que va conociendo, de cuanto siente palpitar incandescente a su alrededor al tiempo que camina. Frecuente es, en consecuencia, el despliegue de los pronombres personales, con cierta 
reminiscencia de La voz a ti debida, para el amante, que vive en una búsqueda perpetua del contacto con el otro en una ausencia presente: "Y yo, a cuestas con tu recuerdo entero / que pesa más que todas las bóvedas del mundo" (Gala 2005: 204); "Tú, Olimpo, me veías / pero a ti yo ya no" (Gala 2005: 211); "Yo me veía en ti: secreto como un libro leído; / en tus pequeños triunfos inventados, / que te forzabas a creer tú mismo, / y en tus desfallecimientos momentáneos..." (Gala 2005: 251); "Recuérdalo, ángel: / el Sur y yo solo en ti pervivimos. / Tú eres el responsable de nosotros" (Gala 2005: 262). Huelga añadir que, en todos los fragmentos que hasta esta parcela he traído a colación, se percibe una corriente discursiva lúcida y pragmática y, por ende, se respeta la exigida perspicuitas, o sea, la claridad del lenguaje.

De la triada de itinerarios que propone Arbillaga, opino que Antonio Gala recurrió, intuitivamente, al denominado itinerario topográfico implícito, a causa de dos circunstancias esenciales que se han atribuido a este. A saber: 1) la plasmación literaria es, subjetivamente, selectiva, desordenada —o mejor, ordenada atendiendo a un criterio disímil al de las banales fechas eliminadas - e incompleta respecto al recorrido real realizado; esto es, en cada ciudad ha seleccionado a placer los rincones o los instantes que, para él, poseen un mayor valor; 2) se percibe que la obra avanza de forma inconexa, en el sentido de que son descritos los lugares principales, y, además, solo en ocasiones excepcionales se da cuenta de los trayectos — y jamás de su duración — que han permitido al protagonista trasladarse de una parte a otra del orbe. El lector acepta, en su pacto silencioso, la elipsis que se experimenta al toparse con quien en esas líneas le relata su divagar en un sitio muy diferente al anterior, a menudo a miles de kilómetros de distancia.

Amén de tal tasación, es de rigor hablar de la representación de la topografía y de la cronografía (Arbillaga 2005: 73-74) en el Tobías. A pesar de que la topografía, como se ha visto, es harto incisiva y podría ser elevada, incluso, en algunos pasajes a la categoría de topotesia — entendida por Lausberg como la descripción detallada de un lugar idílico o ficticio-, son mínimas, en cambio, las salvedades existentes en el poemario que dilucidan cuestiones temporales concretas, y casi nunca apuntándose el sujeto lírico a sí mismo: "Lo que nació para diez mil generaciones / duró trece años solo. / Ciudades sumergidas bajo estanques pueriles" (Gala 2005: 128); y, cuando el tiempo se acerca peligrosamente a su persona, lo expresa, a posta, de modo ambiguo: "Era el día exacto en el que tú moriste" (Gala 2005: 326), procurando reiteradamente borrar su rastro y aligerar, en cierta forma, el equipaje de su lírica de viajes en sacrificio del factor artístico y en aras, quizá, de una suerte de ucronía.

\section{Las huellas del viaje. Algunos contenidos temáticos frecuentes en el género}

\subsection{Los vehículos y el hospedaje}

Hay, no obstante, rociados otros elementos, en forma de contenidos temáticos, que son dignos de atención, los cuales suelen tener cabida en la tradición del generoso género y los cuales resulta preciso señalar. Partamos, para ello, del desenlace de La vuelta al mundo en ochenta días: 
Así, pues, Phileas Fogg había ganado su apuesta. Había cumplido en ochenta días aquel viaje alrededor del mundo. Para ello había empleado todos los medios de transporte: paquebotes, trenes, vehículos, yates, buques de carga, trineos, elefantes (Verne 2010: 300).

Desde una óptica crítica, "acerca del transporte, han dicho Machado y Pageaux que proporciona el primer factor de conocimiento de un espacio extraño por parte del viajante, pues desde luego no es lo mismo ir a pie que en coche o viajar en avión" (Arbillaga 2005: 70). Justo en un aeroplano empieza esta historia con la serie poemática intitulada "Vuelo a Nueva York"2: "Volaba sobre el mar. / Se detenía encima de la luz. / Olía a nube. Coloreaba el horizonte. / Ponía en flor las áridas montañas... / Y no eras tú, era el aire" (Gala 2005: 15). Sin embargo, no es esa travesía por aguas nubosas singular; también disfrutamos de otras tantas como "Vuelo a Finlandia" (Gala 2005: 63-64) o "Vuelo a Thailandia" (Gala 2005: 324-325), y es curioso en grado sumo el trasunto, porque se ha comentado con vehemencia que el avión, acaso, va demasiado rápido y elimina el aura poética del viaje, pero "no es que todo, desde arriba, / parezca pasajero: el que pasa soy yo" (Gala 2005: 268), dice el poeta en su paseo por el cielo. Con piezas de esa talla, nos convenceremos de que no ha de despreciarse a la ligera el viaje en avión, dado que nace, incluso, bella poesía en medio del hastío de los aeropuertos: "Miami. Aeropuerto" (Gala 2005: 151), "Aeropuerto de Ezeiza. Buenos Aires" (Gala 2005: 157) o "Amanecer en el aeropuerto de Ezeiza. Argentina" (Gala 2005: 262-263). Con todo, el propio Antonio Gala reflexionaba en torno a este medio de transporte y argüía:

Ya se vuela, de un punto a otro de la Tierra, en aviones supersónicos, cuyo aparente propósito es despegar hoy y aterrizar ayer, y corren trenes a 250 kilómetros por hora. Yo no llamo viajar a semejante urgencia; yo lo llamo llegar. Para mí viajar es desplazarse, ya que no a pie, a un ritmo que te permita digerir y contemplar la ruta, no ignorarla (Gala 2000: 276).

Hay noticia de que circulan por sus versos más vehículos. Es el caso de "El chófer del taxi", que nos presenta un extraño retrato de un conductor autóctono: "Con tu rostro lampiño / me mirabas por el retrovisor, / y era tu raza sonriente / de pobladas pestañas curvas, / de dentadura blanca, / de altos pómulos / y gruesos labios infantiles: / era tu raza la que me miraba" (Gala 2005: 72-73); "Tu raza, tan ofendida y tan menuda / conducía aquel taxi” (Gala 2005: 73). Este poema, en buena medida, guarda tal vez

2 A pesar de que El poema de Tobias desangelado se inaugura con una serie de veinte composiciones, pertenecientes al bloque "Ministerio del aire", sitas todas en la ciudad de Nueva York, no fue Antonio Gala recogido, por desgracia, en la amplísima Historia poética de Nueva York en la España contemporánea debida al profesor Julio Neira. La relación entre Gala, Nueva York y su historia poética merece otro artículo aparte en el que, actualmente, trabajo.

3 Para una confesión más íntima y pormenorizada sobre los transportes que Antonio Gala ha probado a lo largo de su impresionante vida, acúdase a Gala (2000: 11-32) y a Gala (2000: 280-286) para leer el capítulo "El automóvil y yo" y parte del capítulo "Los viajes y yo", respectivamente. 
el recuerdo del poema "Y el chofer volvía la cara", de José Moreno Villa, en tanto en cuanto en ambos textos se esboza a un conductor de rasgos indígenas que se gira para mirar a los ocupantes del asiento trasero. Inserto en su libro Jacinta la pelirroja, decía: "En aquel taxis, aquella noche, / y en aquel parque, llorando como de verdad, tu naricilla fría y mi barba rapada... / - irecuerdas? - el chofer, curioso y rabioso, / volvía la cara de apache" (Moreno Villa 2000: 82).

En otro orden de comparaciones, si Juan Ramón Jiménez se jactaba en ciertos testimonios de haber escrito ilusionado bajo la influencia de los ritmos del tren algún lindo poemita — este en concreto no se viste de prosa - para Zenobia: "Mientras trabajo, en el anillo de oro / puro me abrazas en la sangre / de mi dedo, que luego sigue, en gozo, / contigo, por toda mi carne" (Jiménez 2011: 104), Gala hacía, melancólico, lo propio - sumando medio de transporte a la envidiable lista - en "Viaje en tren de Córdoba a Madrid": "El habitual paisaje / desfila ante mis ojos. Sin embargo, / tú no estás a mi lado" (Gala 2005: 296).

He descubierto, asimismo, en el texto el uso y disfrute de las embarcaciones. En primera instancia, una inusual, fantástica, pequeña en el poema titulado "Isla Zaona": "Murmuran las grandes velas del catamarán / bajo la mansedumbre de la siesta, / hasta que el viento las hincha y fertiliza. / Ya solos en el mar / [...] canta una voz su complacida queja [...]" (Gala 2005: 82). En instancias intermedias, se adivina la silueta de un barco en varios poemas, aunque no me atrevo a asegurarlo con absoluta rotundidad, puesto que pudieran acusar en la obra un ápice de metáfora, en "Isla Guadalupe": "El barco que nos llevaba juntos / naufragó mientras nos divertía / un simulacro de emergencia... / Fue una noche feliz la última noche" (Gala 2005: 99); o un cariz legendario, incluso, en "San Martín": "Murmuremos aún unas palabras... En esta isla / los marineros seguirán comiendo y navegando; / largarán las velas / al viento que se aíra en tempestades; / comprarán los curiosos / al mediodía inútiles recuerdos [...]" (Gala 2005: 100-101). Con todo, yendo más allá del texto lírico y acudiendo al autobiográfico, pronto se aclara la duda relativa, al menos, a la embarcación del poema "Isla Guadalupe": "Un verano hice un viaje por mar más largo. Acepté la invitación de Miguel de la Quadra, y le acompañé, con sus muchachos de la ruta Quetzal, hasta la isla Guadalupe" (Gala 2000: 285).

Se cataloga, igualmente, en El poema de Tobías desangelado el hospedaje (Arbillaga 2005: 71) del poeta en numerosos lances y, por ende, sus paisajes interiores más íntimos. La Baltasara ${ }^{4}$, su finca paradisíaca de Alhaurín el Grande, provincia de Málaga, es siempre un regreso, sí, pero, al mismo tiempo, es un viaje desde la capital española por lo normal o desde otra localización, siendo en consecuencia el eje axial de los domicilios privados: "Ya han dejado caer sus chorros malvas / las glicinas en torno al cenador / en el que nos aislábamos" (Gala 2005: 293). No obstante, existen otros domicilios privados, verbigracia en Japón (Gala 2005: 86-87). En cuanto a los establecimientos públicos, aparecen, humildes, los albergues: "Ríe la gente, y la cuajada lluvia / golpea

$4 \quad$ En la antología de poemas malagueños bautizada como Desde el Sur te lo digo reuní todos los poemas de Antonio Gala relacionados con Málaga, dedicando un apartado únicamente a los poemas de La Baltasara y reflexionando sobre la significancia de este lugar (Gala 2019). 
con sus recuerdos / el techo, solo el techo, / color miel y alborozado, / de nuestro albergue..." (Gala 2005: 103); y no pocas estancias de diversos hoteles de pesadilla, "Hotel Shangai" (Gala 2005: 130), o de ensueño, "Samarkanda". Uzbekistán":
Sudábamos en la habitación 922,
ante una ciudad latente y arbolada
que era un cuerpo tendido.
Desde la 917 se veían pájaros y cúpulas
como senos de todos los azules.
Te besé entre los cementerios
y en el hombro derecho tenías un antojo
del color de las fresas (Gala 2005: 256).

\subsection{Mirabilia del viaje. Mitologías, leyendas y monumentos}

Asimismo, el poeta peripatético ha observado y escuchado el relato de mitologías, de leyendas antiguas y, en definitiva, de la mirabilia por culturas ajenas a la suya: reafirmación de que somos lo que somos frente a los demás, de que necesitamos a los otros. Particularmente atractivo para ser estudiado a fondo en otro momento se antoja el tema de las religiones en el texto, las cuales se dilucidan y explican brillantemente, porque serían una innovación increíble en la mencionada lectura como cancionero y en sus notas místicas, al otorgar espacio en él a religiones y creencias, en general, desemejantes a la cristiana, a la occidental — propiciando las confluencias y las injerencias- Sea el culto a las momias que deja una nueva e inverosímil prosopografía y trae el recuerdo del antiguo Egipto: "Los grandes ojos. La nariz pequeña... / Falta tu brazo izquierdo [...]" (Gala 2005: 71), "Las piernas, en un giro improbable, / desechadas como desecha el ángel / los pies que le entorpecen caminar" (Gala 2005: 71); sean los exóticos dioses indígenas de los nativos de América del Sur: "Ehécatl, dios del viento. / El Viento enmascarado / igual que el dios del vino, / inalcanzable, torcido irrepetible, / con la sierpe emplumada / sobre los hombros, que el viento / de fuera agita y riza..." (Gala 2005: 76); sea el eco panteísta del lejano oriente y la fascinación que suscitan sus criaturas ancestrales: "Eres mi Rey Mono, invencible aliado, / mi isla con el Templo del Dragón, / dentro de mi lago artificial, / y mi dragón más blanco / que, por algún error desconocido, / no puede apenas caminar. / Eres mi Templo del Incienso de Buda, / tan bello en lo alto solamente, / desde la Puerta que Aleja las Nubes..." (Gala 2005: 122); sea el desbordamiento del islam, de lo arábigo, que Gala tanto ha amado en su vasta opera": "Y en la mezquita de Chej Mejidin, / entre neones que rasgan los grandes capiteles / de hoja de acanto, prosternado, / adoro al mismo dios de amor que tú adoraste, / y no lo adoro solo" (Gala 2005: 139); o sean los fulgores — luces y sombras— de la Hélade:

$5 \quad$ Anecdóticamente, posee Gala una obra dramatúrgica cuasi homónima: Samarkanda. Para un análisis detallado de esta puede consultarse Romera Castillo (1986).

6 Existe, por cierto, incluso una extensa tesis doctoral - que flaquea, por desgracia, en la falta del análisis del corpus poético en relación con el componente arábigo - al respecto: Aspectos arábigo-andaluces en la producción literaria de Antonio Gala (Badri Guezza 2016). 
"Aquí maldijo Clitemnestra / el olor de su sangre. / Aquí Orestes gritó. Aquí / besó en la boca a Pílades. / Lo que vino después fue somnolencia" (Gala 2005: 175). Y lo alucinante, después de este repaso, es lo que llena de sentido y de trascendencia tanta opulencia por y hacia las deidades para Antonio Gala: "Y de repente, bajo nuestra mirada, / una gata y sus siete gatitos, apiñados, / justificaron esta catedral / donde viven y se aman" (Gala 2005: 72).

El escritor andariego ha ido cosechando, de otra parte, para su poesía de viajes también los monumentos con que fue topando en su camino, en su peregrinatio vitae emanada de una peregrinatio amoris, la cotidianeidad de la región que lo impregnaba y hasta la fisionomía de la urbe que lo alojaba ${ }^{7}$. Ciertamente, la nómina es inmensa, así es que solo mencionaré ahora algunos versos del ejemplo que pienso que está más logrado y mejor materializado, el cual brota encadenando sus eslabones en Viena y traza una panorámica perfecta de la ciudad, recogiendo las plantas de sus jardines, sus edificios más emblemáticos, sus calles más famosas e, incluso, su cultura dorada: "Tú solo eres mi vals, mis tulipanes, / mi taraje palo de rosa, mi Palas Atenea, / mi Teatro y mi Ayuntamiento, / mi inocente Avenida del Anillo / y mi Prater ruidoso y sus castaños / y mi Ópera con toda su armonía. / Tú eres mi atardecer y mi alameda, / mi sed y mi agua fresca, / mi música de Mozart...” (Gala 2005: 201).

\subsection{Otros aspectos restantes: el compañero de viaje, las llegadas y las despedidas}

Finalmente, recogía Arbillaga tres aspectos más (Arbillaga 2005: 71-72) que resultan de provecho para el presente asedio:

1) La figura del compañero de viaje, la cual encarna en este poemario el ángel, esa presencia inmutable o esa ausencia sempiterna, en sus tres facetas: el arcángel San Rafael bíblico, el amor y el propio amado. No está de más comentar que verdaderos compañeros de viaje como el secretario Luis Cárdenas o amigos suyos han sido difuminados en la niebla lírica mientras que en Ahora hablaré de mí, su autobiografía, sí que aparecen.

2) La llegada al país que le da la bienvenida, a veces de forma anticipada: "Antes de haber llegado, sobre el Empire State / oponiéndote al aire. / Y el aire te llevaba" (Gala 2005: 12); a veces in situ, por ejemplo, en la cuna presuntamente natal del amado, camuflada en "Un pueblo visitado": "Aquí naciste tú, áptero todavía. / Te embelleciste bajo estas palmeras, / oíste acaso estos pájaros / y te bañaste en esta luz los ojos" (Gala 2005: 247).

3) Y, por último, algo más acostumbrada, la salida del país —era Rilke quien sostenía que los seres humanos vivimos en constante despedida - así "Caracas. Despedida": "Todo quedará igual / que cuando lo encontré. / Igual, pero sin mí: / como tu vida" (Gala 2005: 154), incidiendo nuevamente en el vínculo entre el sujeto y el entorno a través del amor.

7 Destaca, en el trasunto de las relaciones entre los literatos y las ciudades, el libro El impuro amor de las ciudades (Notas acerca de la literatura modernista y el espacio urbano) (2002), de Álvaro Salvador Jofre (Casa de las Américas, La Habana). En lo relativo a Gala, sería interesante comparar su acercamiento a las capitales hispanoamericanas con el de los autores recogidos por Salvador. 
Por si queda, llegados al delta de este trabajo, atisbo alguno de duda sobre la naturaleza del poliédrico Tobías como ejemplar de la lírica de viajes, valga una última perla artística, confesional, del capítulo "Los viajes y yo" (Gala 2000: 276-287), rescatada de Ahora hablaré de mí, en tanto que gozaba Gala del paisaje desde la ventanilla de un tren en marcha:

[...] a lo lejos, en las casitas solas, imagino lo que sucede en ellas, retorno los ojos al libro no leído, tengo todo el tiempo entre las manos, lo acaricio, lo disfruto; no estoy ya en el trabajo de ayer, tampoco todavía en el de mañana... Amo viajar con el regalo de ese tiempo con el que no se cuenta, ese tiempo de más, esa imaginaria abundancia en la que brota con tanta naturalidad el poema. No es extraño que jamás se termine mi libro Tobias desangelado, que al fin es un libro de viajes... (Gala 2000: 280).

\section{Conclusiones después del viaje}

Se ha delineado en este artículo uno de los perfiles de El poema de Tobías desangelado, la lectura en clave de lírica de viajes —una peregrinatio vitae - la cual podría identificarse con la historia del asedio de una ciudad (Borges 1974: 1128) —o, reinventada y revertida, del héroe asediado, a menudo, por una turba inmensa de ciudades-. De tal suerte, antes de la partida se ha revisado el equipaje preparado, y en él se han hallado las columnas retóricas exigidas para hablar, con propiedad, de una obra perteneciente a la literatura de viajes e, igualmente, se ha hallado la constatación inexcusable de la topografía, que superaba con creces a la cronografía, dado que esta se borró, a posta y con disimulo, del lírico cuaderno de viajes. Tras regresar de la aventura, se ha pasado revista a la bolsa con los recuerdos provenientes del periplo por el orbe de Antonio Gala: los vehículos utilizados, los hospedajes, el contacto con otras tantas culturas, sus religiones, sus monumentos, el compañero de peripecias, etcétera, regalando a los lectores, al final, una experiencia tan asombrosa como inolvidable para los sentidos. Con todo, se ha presentado deductivamente un caso ejemplar de la lírica de viajes, rara avis, y se ha empezado a compensar la dejadez crítica frente a lírica del autor con objeto de ponerla en valor: "En la actualidad, la práctica poética de Antonio Gala sigue siendo una tarea pendiente en el seno de los estudios literarios" (Cobo Guijarro y Padilla Mangas 2019: 394).

Ojalá haya alcanzado este breve asedio, a la postre, después de este agradable paseo por todos los paisajes de Gala, apoyar y demostrar la hipótesis inicial, obteniendo una muestra paradigmática, pionera y completa de la lírica de viajes, una nueva etiqueta aquí propuesta tras denunciar la problemática existente al respecto. Es esta, sin duda, una obra valiosa de vida y arte, la cual ha sido encomendada a los lectores con muchos esfuerzos vitales y poéticos del autor, en tanto en cuanto su escritura se desarrolló a lo largo de casi cuarenta años de amor y de viajes. Ya lo decía Julio Verne: "Verdaderamente, ¿no daría cualquiera por menos la vuelta al mundo?" (Verne 2010: 300).

\section{BIBLIOGRAFÍA}

ALBURQUERQUE GARCÍA, Luis (coord.) (2011): Relatos y literatura de viajes en el ámbito hispánico: poética e historia [http://revistadeliteratura.revistas.csic.es/ 
index.php/revistadeliteratura/issue/view/23; 05/06/2018]. Número monográfico de Revista de Literatura, vol. LXXIII, núm. 145.

ARANDA, Verónica (2010): Cortes de luz. Madrid: Ediciones Rialp.

ARBILLAGA, Idoia (2005): Estética y teoría del libro de viaje: El "viaje a Italia" en España, anejo LV de Analecta Malacitana. Málaga: Universidad de Málaga.

ARENAS HARO, Miguel Ángel (2005): Polisgamia, Certamen de Jóvenes Artistas de Castilla-La Mancha 2005. Albacete: Junta de Comunidades de Castilla-La Mancha. Consejería de Relaciones Institucionales, 29-34.

BADRI GUEZZA, Naïma (2016): Aspectos arábigo-andaluces en la producción literaria de Antonio Gala [http://eprints.ucm.es/39728/; 05/06/2018], tesis doctoral dirigida por Francisca Rubio Gámez. Universidad Complutense de Madrid.

BORGES, Jorge Luis (1974): Obras completas. Buenos Aires: Emecé Editores.

CABALLERO BONALD, José Manuel (2011): "La expresión poética de Antonio Gala", Ana Padilla Mangas (coord.), Antonio Gala y el arte de la palabra. Córdoba: Servicio de Publicaciones de la Universidad de Córdoba, 25-32.

COBO GUIJARRO, Clara; PADILLA MANGAS, Ana (2019): "El legado literario de Antonio Gala: estado de la cuestión" [http://www.creneida.com/revista/ creneida-7-2019/el-legado-literario-de-antonio-gala-estado-de-la-cuestiónclara-cobo-y-ana-padilla/; 15/06/2020]. Creneida, núm. 7, 372-407.

DÍAZ DE CASTRO, Francisco (2005): "El poema de Tobías desangelado. Antonio Gala” [http://www.elcultural.com/revista/letras/El-poema-de-Tobias-desangelado/15997; 22/05/2020]. El Cultural.

EFE (2005): "Antonio Gala presenta El poema de Tobías desangelado, su «testamento literario»" [https://elpais.com/cultura/2005/11/14/actualidad/1131922801_850215. html; 22/05/2019]. El País.

GALA, Antonio (1997): Poemas de amor, prólogo y edición de Pere Gimferrer. Barcelona: Editorial Planeta.

(1998): Testamento andaluz. Córdoba: CajaSur. Obra Social y Cultural.

(2000): Ahora hablaré de mí. Barcelona: Editorial Planeta.

(2005): El poema de Tobías desangelado. Barcelona: Editorial Planeta.

(2018): "Palabras previas para los ángeles peregrinos", Silvestro Neri y Lorenzo Cittadini (eds.), Quaderni Mediterranei. Poeti traduttori in viaggio. Volume I. Ponte di Piave: La Piave Editore, 15-16.

(2019): Desde el Sur te lo digo, edición de Pedro J. Plaza González. Málaga: "Arroyo de la Manía", núms. 10-11, Rafael Inglada Ediciones.

GARRIDO GALLARDO, Miguel Ángel (1994): "Géneros literarios", Darío Villanueva (coord.), Curso de teoría de la literatura. Madrid: "Lingüística y Filología”, Taurus Universitaria, 165-189.

INFANTE, José (1994): Antonio Gala, un hombre aparte. Madrid: Espasa Calpe.

JIMÉNEZ, Juan Ramón (2011 [1998]): Diario de un poeta reciencasado (1916), edición de Michael P. Predmore. Madrid: "Letras Hispánicas”, Ediciones Cátedra.

KAVAFIS, Konstantino (1997 [1976]): Poesías completas, traducción y notas de José María Álvarez. Madrid: Ediciones Hiperión. 
LARA GARRIDO, José (1999): Los mejores plectros. Teoría y práctica de la épica culta en el Siglo de Oro, anejo XXIII de Analecta Malacitana. Málaga: Universidad de Málaga.

MORENO VILLA, José (2000): Jacinta la pelirroja, edición de Rafael Ballesteros y Julio Neira. Madrid: "Clásicos Castalia", Editorial Castalia.

NEIRA, Julio (2012): Historia poética de Nueva York en la España contemporánea. Madrid: Ediciones Cátedra.

PEÑALTA CATALÁN, Rocío (2014): La proyección estético-literaria de un modelo urbano: la ciudad de Venecia [http://eprints.ucm.es/29980/1/T36031.pdf; 26/05/2018], tesis doctoral dirigida por Eugenia Popeanga Chelaru. Universidad Complutense de Madrid.

ROMERA CASTILLO, José (1986): "Samarkanda, de Antonio Gala" [https://cvc.cervantes.es/literatura/aih/aih_ix.htm; 05/06/2018], Sebastian Neumeister (dir.), Actas del IX Congreso de la Asociación Internacional de Hispanistas, 363-371.

RUBIO, Fanny (2016): "La voz que acuna los pliegues del canto", Isabel Martínez Moreno (ed.), Antonio Gala. Eterno y de cristal. Sevilla: Junta de Andalucía, Consejería de Cultura, 150-157.

SALCINES DE DELÁS, Diana (1995): La literatura de viajes: Una encrucijada de textos [http://eprints.ucm.es/3666/; 05/06/2018], tesis doctoral dirigida por Eugenia Popeanga Chelaru. Universidad Complutense de Madrid.

SANTOS ROVIRA, José María; ENCINAS ARQUERO, Pablo (2009): "Breve aproximación al concepto de literatura de viajes como género literario" [https://digitum.um.es/digitum/handle/10201/43357; 15/06/2020]. Tonos Digital, núm. 17.

URBAIN, Jean-Didier (1993): El idiota que viaja: Relatos de turistas, traducción de Soledad Guilarte Gutiérrez. Madrid: Endymion.

VERNE, Julio (2010 [1984]): La vuelta al mundo en ochenta días. Madrid: Akal.

\section{PERFIL ACADÉMICO Y PROFESIONAL}

Pedro J. Plaza González es investigador FPU de la Universidad de Málaga y colabora, en la actualidad, en publicaciones como Quaderni Mediterranei, Clarín o Zenda. Forma parte, además, del equipo multidisciplinar de Cornvcopia y El Toro Celeste y ha comenzado los primeros pasos de su tesis doctoral en torno a la obra poética de Gala, la cual ha venido a titularse Tradición y modernidad en la poesía de Antonio Gala: Exégesis y relección desde su obra total. Ha traducido al español Cantos suspendidos entre la tierra y el cielo (Editorial Independiente, 2017), del poeta italiano Silvestro Neri, y ha quedado a su cuidado la edición de Desde el Sur te lo digo (Rafael Inglada Ediciones, 2019), antología que recoge los poemas malagueños de Gala. Es miembro del grupo «Andalucía Literaria y Crítica: Textos Inéditos y Relecciones» (HUM233), proyecto en el que se inscribe el presente trabajo.

Fecha de recepción: 30/04/2020

Fecha de aceptación: 14/07/2020 